\title{
Treatment package time predicts cancer-specific survival and distant metastasis in laryngeal cancer
}

\author{
HIDENORI SUZUKI ${ }^{1}$, HOSHINO TERADA ${ }^{1}$, NOBUHIRO HANAI ${ }^{1}$, DAISUKE NISHIKAWA ${ }^{1}$, \\ YUSUKE KOIDE ${ }^{1}$, SHINTARO BEPPU ${ }^{1}$, TAKESHI KODAIRA ${ }^{2}$, HIROYUKI TACHIBANA ${ }^{2}$, \\ YUTARO KOIDE $^{2}$, HIROSHI TANAKA ${ }^{2}$ and YASUHISA HASEGAWA ${ }^{2}$ \\ Departments of ${ }^{1}$ Head and Neck Surgery, and ${ }^{2}$ Radiation Oncology, Aichi Cancer Center Hospital, \\ Nagoya, Aichi 464-8681, Japan
}

Received July 12, 2018; Accepted October 26, 2018

DOI: $10.3892 / \mathrm{ol} .2018 .9664$

\begin{abstract}
We investigated whether treatment package time was significantly associated with survival outcomes of resectable locally-advanced laryngeal squamous cell carcinoma in patients who consecutively underwent various treatments, including surgery alone and salvage surgery for residual tumor. A total of 100 patients with clinical T3-T4 resectable laryngeal squamous cell carcinoma were enrolled in this study. The treatment package time was calculated in days between the start of any treatment and the end of all treatments, including postoperative radiotherapy and salvage surgery for residual tumors. Using a log-rank test, a treatment package time of $\geq 68$ days showed significantly shorter cancer-specific $(\mathrm{P}=0.0013)$ and distant metastasis-free survival $(\mathrm{P}=0.0017)$, compared with a treatment package time of $<68$ days. Multivariate survival analyses of two Cox's hazards proportional models was conducted. In both model-1, which adjusted for cT3/cT4, cN0-1/cN2-3 and total laryngectomy/non-total laryngectomy, and model-2, which adjusted for cT3/cT4, cN0-1/cN2-3 and induction therapy/non-induction therapy, the cancer-specific survival and distant metastasis-free survival, according to treatment package time, were significantly longer with $<68$ days compared with $\geq 68$ days $(\mathrm{P}<0.01)$. The present study demonstrated that a prolonged treatment package time is a prognostic factor for shorter cancer-specific and distant
\end{abstract}

Correspondence to: Dr Hidenori Suzuki, Department of Head and Neck Surgery, Aichi Cancer Center Hospital, 1-1 Kanokoden, Nagoya, Aichi 464-8681, Japan

E-mail: hi.suzuki@aichi-cc.jp

Abbreviations: ACRT, alternating chemoradiotherapy; CRT, concurrent chemoradiotherapy; CSS, cancer-specific survival; DMFS, distant metastasis-free survival; LALSCC, locally-advanced laryngeal squamous cell carcinoma; LRRFS, locoregional recurrence-free survival; OS, overall survival; PL, partial laryngectomy; RT, radiotherapy; TL, total laryngectomy; TNM, tumor-node metastasis; TPT, treatment package time

Key words: LALSCC, TPT, CSS, DMFS, prognostic factor metastasis-free survival after various treatments for resectable locally-advanced laryngeal cancer.

\section{Introduction}

Total laryngectomy $(\mathrm{TL}) \pm$ radiotherapy $(\mathrm{RT})$ had been the classical treatment for resectable locally-advanced laryngeal squamous cell carcinoma (LALSCC), which is classified as clinical T3-T4a disease (1). Various organ-preserving treatment modalities, including partial laryngectomy (PL), concurrent chemoradiotherapy (CRT), chemoselection from induction chemotherapy have been performed for resectable LALSCC (1-5). We have also showed the efficacy of alternating chemoradiotherapy (ACRT) with early assessment following induction of CRT and salvage surgery for residual tumors in resectable LALSCC (6). Although the tumor-node metastasis (TNM) classification of resectable LALSCC is globally used as the prognostic factor of survival outcomes, such as cancer-specific survival (CSS), after various treatments, the same TNM classification is unable to predict survival outcomes (2-4). Recently, the prognostic factors for resectable LALSCC have been investigated by various approaches (2-4,7-10).

Treatment package time (TPT), which is similar to overall treatment time, is calculated from the start of any treatment to the end of all treatments and had been shown as a prognostic factor in several cancers (3,4,7-10). Prolonged TPT of several modalities, including RT alone and surgery with postoperative RT, has been reported to be a predictor of worse CSS for head and neck cancer (3).

To the best of our knowledge, the association between survival outcomes and TPT in patients with resectable LALSCC, who consecutively underwent various treatments, including surgery alone and salvage surgery for residual tumor, has not been previously investigated. In the present study, we investigated whether TPT was significantly associated with survival outcomes of resectable LALSCC in patients who consecutively underwent various treatments, including surgery alone and salvage surgery for residual tumor.

\section{Materials and methods}

Patients. Between 2004 June and 2016 October, 101 patients who were newly diagnosed as clinical T3-T4a laryngeal 
squamous cell carcinoma consecutively underwent definitive treatment at the Aichi Cancer Center Hospital. After excluding one patient who diagnosed as cN3 with unresectable disease, a total of 100 patients with resectable LALSCC were enrolled in this study. This study was approved by the review board of Aichi Cancer Center Hospital, and informed consent for the examinations and treatments was obtained from all of the patients. The subsites of the primary tumor were the supraglottis $(n=64)$, glottis $(n=32)$, and subglottis $(n=4)$. Clinical staging based on the TNM classification of the seventh edition of the International Union Against was determined from routine physical examination, flexible laryngeal endoscope, enhanced cervical computed tomography, and 18F-FDG-PET/CT, if possible. The Charlson comorbidity index, which was a weighted index, was calculated from 19 comorbid conditions.

Initial treatment. The 100 patients were classified based on initial treatment of the primary tumor: TL \pm RT with or without chemotherapy (TL, $n=27)$; PL (PL, $n=5)$; concurrent $\mathrm{CRT} \pm$ salvage surgery for residual tumor $(\mathrm{CRT}, \mathrm{n}=11)$; induction CRT followed by CRT \pm salvage surgery for residual tumor to responders or TL $\pm \mathrm{RT}$ with or without chemotherapy to non-responders (ACRT, $n=27$ ); induction chemotherapy following concurrent RT with or without chemotherapy \pm salvage surgery for residual tumor to responders or $\mathrm{TL} \pm \mathrm{RT}$ with or without chemotherapy to non-responders (chemoselection, $\mathrm{n}=27$ ); and RT alone \pm salvage surgery for residual tumor (RT alone, $\mathrm{n}=3$ ). We recommended postoperative RT with or without chemotherapy to patients with multiple lymph node metastasis, extranodal extension, and positive resection margin. Salvage surgery was performed for residual tumor found on pathological and imaging examination at 1-2 months after the completion of RT with or without chemotherapy, as described previously (11). After completion of the initial treatments, including salvage surgery for residual tumor, we made an effort to perform salvage surgery based on the presence of tumor recurrence.

Selection of initial treatment. The recommended treatment of choice was TL, but for patients who wished not to undergo surgery, we initially selected concurrent CRT or RT alone in those with advanced age or who refused chemotherapy. For patients who required maximal organ preservation without a reduction in treatment efficacy, ACRT was selected from January 2004 to January 2011 if consistent with the protocol; after February 2011, most patients underwent chemoselection. Patients who wished organ preservation and refused RT underwent PL. The details of the en bloc dissection, RT procedures, chemotherapy regimens, and the selection of primary treatment have been reported elsewhere $(6,11-14)$. In brief, definitive RT was given at a total dose of 66-70 Gy with 2 Gy per fraction; induction chemotherapy was given mostly by intravenous infusion of 5-fluorouracil and cisplatin, the regimens of concurrent CRT were triweekly or weekly cisplatin, and weekly cetuximab.

Time to treatment initiation and TPT. According to previous reports $(9,14)$, the time to treatment initiation was calculated in days from the time of pathological diagnosis of LALSCC to the start of any treatment; TPT was likewise calculated in days from the start of any treatment to the end of all treatments, including postoperative RT and salvage surgery for residual tumor.

Statistical analysis. Statistical analyses were carried out using the JMP software package (version 9; SAS Institute, Inc., Cary, NC, USA). The best cut-off values for time to treatment initiation or TPT for death due to LALSCC were assessed by receiver-operating characteristic curve (ROC) analysis, as described previously (12). ROC analysis in the present study was performed by using TPT or the time to treatment initiation, as continuous variables. Survival time, which was calculated as the number of days from the start of any treatment to a target event or last contact, was analyzed by the Kaplan-Meier method. The target events were death for overall survival (OS), death due to LALSCC for CSS, local or regional recurrence for locoregional recurrence-free survival (LRRFS), and distant metastasis for distant metastasis-free survival (DMFS). The patients were categorized into two groups based on their TPT ( $<68$ days vs. $\geq 68$ days); differences between the two groups were compared by univariate survival analysis using a log-rank test. Another grouping, using, using two models, was based on the initial treatment of the primary tumor; model 1 was TL $(n=27)$ and the non-TL $(n=73)$ groups, whereas model 2 compared the induction group, which included ACRT and chemoselection $(n=54)$, and the non-induction group $(n=46)$. The associations between the two groups (TPT $<68$ days or TPT $\geq 68$ days) with regard to the clinical characteristics (cT and $\mathrm{cN}$ classification, cStage, subsite, vocal cord fixtation, charlson comorbidity index, gender, age, adjuvant treatment, initial treatment, treatment group) were compared by using chi-squared test or Fisher's exact test. Multivariate analyses for the factors associated with CSS and DMFS used two Cox's proportional hazards models. Model-1 was adjusted with the cT (cT3/cT4), cN (cN0-1/cN2-3), TPT (<68 days/ $\geq 68$ days), and treatment group (TL/non-TL). Model-2 was adjusted with the cT (cT3/cT4), cN (cN0-1/cN2-3), TPT (<68 days/ $\geq 68$ days), and treatment group (induction/non-induction). $\mathrm{P}<0.05$ was considered to indicate a statistically significant difference.

\section{Results}

Clinical characteristics. The clinical characteristics of the population are shown in Table I. At the end of the study, the mean \pm SD follow-up period was $1317 \pm 930$ days among all patients, $1,478 \pm 961$ days for the 68 patients who remained alive, $976 \pm 768$ days for the 32 patients who died, and $1,000 \pm 716$ days for the 20 patients who died due to LALSCC. The mean \pm SD of the time to treatment initiation and TPT were $26.0 \pm 13.1$ days and $58.3 \pm 51.4$ days, respectively. The association between TPT and number of patients were shown in Fig. 1. Locoregional recurrence and distant metastasis were found in 25 and 17 patients, respectively. TL on initial treatment, including salvage surgery, was performed on 46 patients with residual tumor and on nine patients with recurrence tumor. The overall five-year rates for OS, CSS, LRRFS, and DMFS were 68.9, 78.0, 70.9, and 76.3\%, respectively. 
Table I. Characteristics of initial treatment in 100 patients with laryngeal squamous cell carcinoma.

\begin{tabular}{|c|c|c|c|c|c|c|c|}
\hline \multirow[b]{2}{*}{ Characteristics } & \multirow[b]{2}{*}{ Total } & \multicolumn{6}{|c|}{ Initial treatment } \\
\hline & & $\mathrm{TL}$ & PL & $\begin{array}{c}\text { Concurrent } \\
\text { RT }\end{array}$ & ACRT & $\begin{array}{l}\text { Chemo- } \\
\text { selection }\end{array}$ & RT alone \\
\hline & 100 & 27 & 5 & 11 & 27 & 27 & 3 \\
\hline $\mathrm{cT}, \mathrm{cT} 3 / \mathrm{cT} 4$ & $72 / 28$ & $19 / 8$ & $4 / 1$ & $11 / 0$ & $20 / 7$ & $16 / 11$ & $2 / 1$ \\
\hline \multicolumn{8}{|l|}{$\mathrm{cN}$} \\
\hline $\mathrm{cN} 0 / \mathrm{cN} 1$ & $59 / 13$ & $17 / 4$ & $5 / 0$ & $8 / 0$ & $14 / 5$ & $12 / 4$ & $3 / 0$ \\
\hline $\mathrm{cN} 2 / \mathrm{cN} 3$ & $26 / 2$ & $5 / 1$ & $0 / 0$ & $3 / 0$ & $8 / 0$ & $10 / 1$ & $0 / 0$ \\
\hline cStage, cStageIII/cStageIV & $57 / 43$ & $17 / 10$ & $4 / 1$ & $8 / 3$ & $15 / 12$ & $11 / 16$ & $2 / 1$ \\
\hline Charlson comorbidity index, $0 / \geq 1$ & $37 / 63$ & $10 / 17$ & $1 / 4$ & $1 / 10$ & $15 / 12$ & $8 / 19$ & $1 / 2$ \\
\hline Sex, male/female & $94 / 6$ & $24 / 3$ & $5 / 0$ & $11 / 0$ & $25 / 2$ & $26 / 1$ & $3 / 0$ \\
\hline Subsite, supraglottis/glottis/subglottis & $64 / 32 / 4$ & $18 / 8 / 1$ & $1 / 4 / 0$ & $8 / 3 / 0$ & $16 / 10 / 1$ & $19 / 6 / 2$ & $2 / 1 / 0$ \\
\hline Vocal cord fixation, presence/absence & $44 / 56$ & $18 / 9$ & $0 / 5$ & $3 / 8$ & $16 / 11$ & $19 / 8$ & $1 / 2$ \\
\hline Age & $67.4 \pm 8.1$ & $72.9 \pm 8.6$ & $69.2 \pm 6.7$ & $69.7 \pm 6.9$ & $63.1 \pm 7.3$ & $65.9 \pm 5.4$ & $61.7 \pm 9.0$ \\
\hline Treatment package time, days & $58.3 \pm 51.4$ & $8.8 \pm 24.0$ & $1 \pm 0$ & $65.3 \pm 32.6$ & $77.9 \pm 41.2$ & $92.6 \pm 46.4$ & $87.3 \pm 61.2$ \\
\hline Time to initiation & $26.0 \pm 13.1$ & $31.4 \pm 18.7$ & $33.2 \pm 3.0$ & $29.3 \pm 7.3$ & $20.3 \pm 8.9$ & $24.0 \pm 8.4$ & $21.7 \pm 14.2$ \\
\hline $\begin{array}{l}\text { Adjuvant treatment, PORT(POCRT)/salvage } \\
\text { surgery/no }\end{array}$ & $6 / 10 / 84$ & $3 / 0 / 24$ & $0 / 0 / 5$ & 0/3/8 & $0 / 3 / 24$ & $3 / 3 / 23$ & $0 / 1 / 2$ \\
\hline \multicolumn{8}{|l|}{ Outcomes } \\
\hline Follow-up, days & $1317 \pm 930$ & $1012 \pm 727$ & $524 \pm 262$ & $846 \pm 680$ & $2123 \pm 1031$ & $1189 \pm 663$ & $1016 \pm 882$ \\
\hline $\begin{array}{l}\text { Laryngectomy, initial/salvage for } \\
\text { recurrence/no }\end{array}$ & $46 / 9 / 45$ & $27 / 0 / 0$ & $0 / 0 / 5$ & $0 / 2 / 9$ & $5 / 5 / 17$ & $12 / 2 / 13$ & $2 / 0 / 1$ \\
\hline $\begin{array}{l}\text { Recurrence or metastasis, } \\
\text { locoregional/distant/none }\end{array}$ & $25 / 17 / 58$ & $5 / 4 / 18$ & $1 / 0 / 4$ & $4 / 1 / 6$ & $5 / 3 / 19$ & $9 / 8 / 10$ & $1 / 1 / 1$ \\
\hline Survival, alive/cancer death/others death & $68 / 20 / 12$ & $16 / 5 / 6$ & $5 / 0 / 0$ & $6 / 2 / 3$ & $20 / 4 / 3$ & $20 / 7 / 0$ & $1 / 2 / 0$ \\
\hline
\end{tabular}

ROC analysis. From the ROC analyses, the best cut-off values for time to treatment initiation and TPT to detection of death from $\mathrm{LALSCC}$ were 15 days $(\mathrm{AUC}=0.50, \mathrm{P}=0.81$ ) and 68 days (AUC $=0.73, \mathrm{P}<0.01$ ), respectively. The ROC, AUC of the ROC, sensitivity, and 1-specificity of TPT for death from LALSCC are shown in Fig. 2; the time to treatment initiation for death from LALSCC was additionally determined (data not shown).

Univariate survival analysis. Compared with patients with TPT $<68$ days, those with TPT $\geq 68$ days had significantly shorter CSS $(\mathrm{P}=0.0013)$ and DMFS $(\mathrm{P}=0.0017)$. On the other hand, the two groups of TPT had no difference in the OS $(\mathrm{P}=0.08)$ and LRRFS $(\mathrm{P}=0.16)$. The Kaplan-Meier curves for CSS and DMFS are shown in Figs. 3 and 4, respectively.

TPT and clinical characteristics. The associations between the TPT and clinical characteristics are shown in Table II. Compared with patients with TPT $<68$ days, those with TPT $\geq 68$ days had significantly higher number of patients of $\mathrm{cN} 2-3$ disease $(\mathrm{P}=0.02)$, who received adjuvant treatment $(\mathrm{P}<0.01)$, initial treatment $(\mathrm{P}<0.01)$, in the TL group $(\mathrm{P}<0.01)$ and the induction therapy group $(\mathrm{P}<0.01)$.
Multivariate survival analysis. The results of the multivariate analyses for CSS and DMFS are shown in Table III. In model $1, \mathrm{cN} 0-1(\mathrm{P}=0.02)$, TPT $<68$ days $(\mathrm{P}<0.01)$, and the non-TL group $(\mathrm{P}=0.02)$ were significantly associated with a longer CSS, and $\mathrm{cN} 0-1(\mathrm{P}<0.01)$, TPT $<68$ days $(\mathrm{P}<0.01)$, and the non-TL group $(\mathrm{P}=0.03)$ were significantly associated with a longer DMFS. In mode 2, cN0-1 ( $\mathrm{P}=0.01)$, TPT $<68$ days $(\mathrm{P}<0.01)$, and the induction therapy group $(\mathrm{P}<0.01)$ were significantly associated with longer CSS, and $\mathrm{cN} 0-1$ $(\mathrm{P}<0.01)$, TPT $<68$ days $(\mathrm{P}<0.01)$, and the induction therapy group $(\mathrm{P}=0.02)$ were significantly associated with longer DMFS.

\section{Discussion}

In the present study, we showed for the first time that a TPT of $\geq 68$ days was significantly associated with shorter CSS and DMFS in patients with resectable LALSCC who consecutively underwent various treatments, including surgery alone and salvage surgery for residual tumor.

Various organ-preserving treatments modalities are being offered in clinical practice, and several trials have reported on 


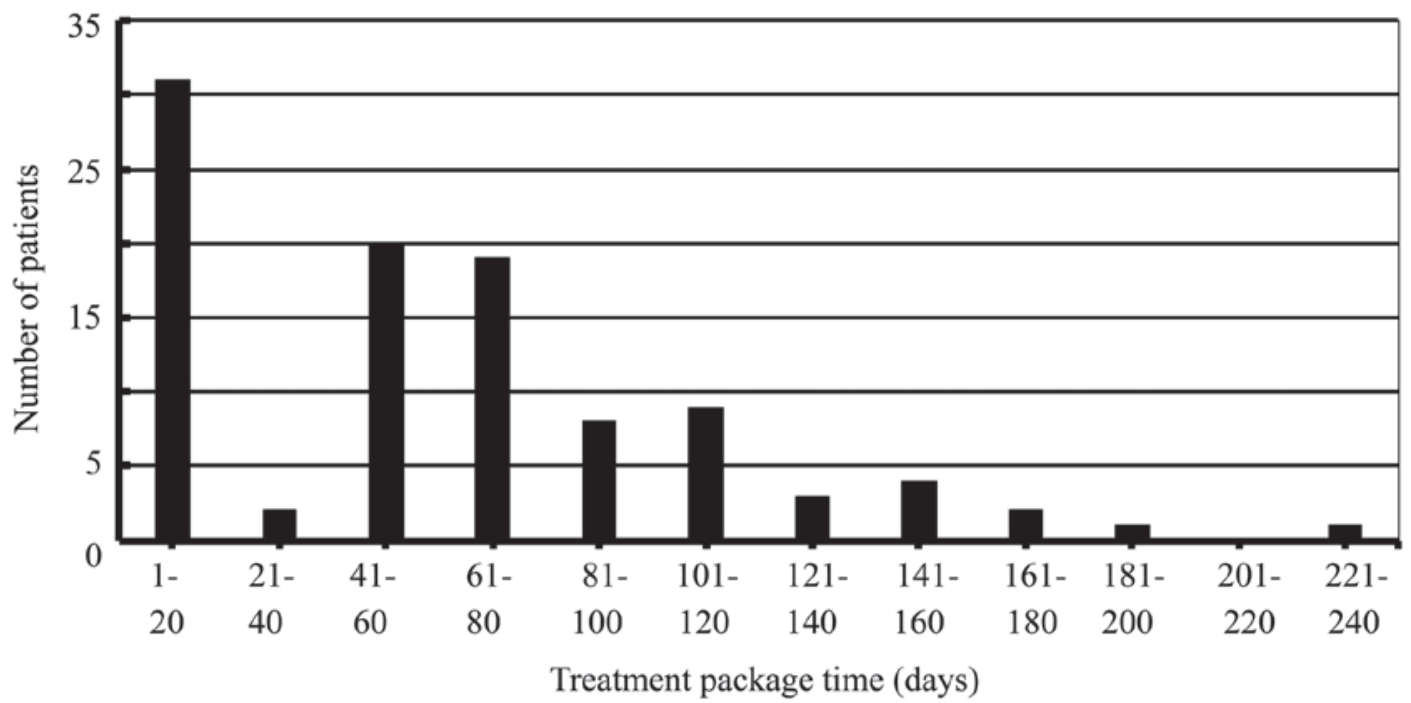

Figure 1. Association between the treatment package time and the number of patients with resectable locally-advanced laryngeal squamous cell carcinoma $(n=100)$.

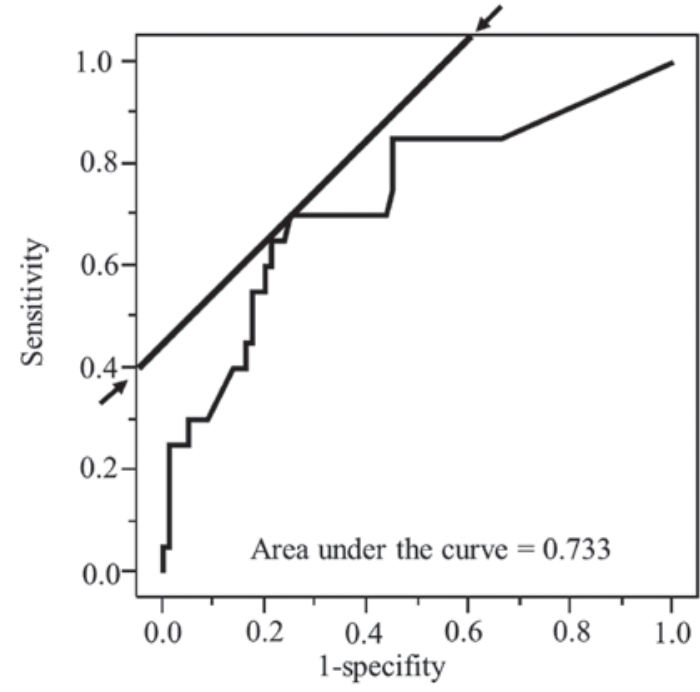

Figure 2. Receiver-operating characteristic curves on the best cut-off value of treatment package time for death from resectable locally-advanced laryngeal squamous cell carcinoma. The straight line between arrows within the plot was drawn at a 45 degree angle tangent to the Receiver-operating characteristic curves.

concurrent CRT vs. induction following CRT (1-5). We have also shown the efficacy of ACRT with early assessment for laryngeal squamous cell carcinoma and that of chemoselection for several cancer sites, including the hypopharynx and cervical esophagus (6,11-13).

The TPT as time factor of several treatment modalities, including RT alone, concurrent CRT, and surgery with postoperative CRT, has been shown to be a prognostic factor in several types of cancer, including laryngeal cancer (3,7-10). We also investigated the association between survival outcomes and the time factors of several treatments, including ACRT, in hypopharyngeal cancer (11). To the best of our knowledge, the association between survival outcomes and TPT of various treatments, including surgery alone, chemoselection, and ACRT with salvage surgery for residual tumor, has not

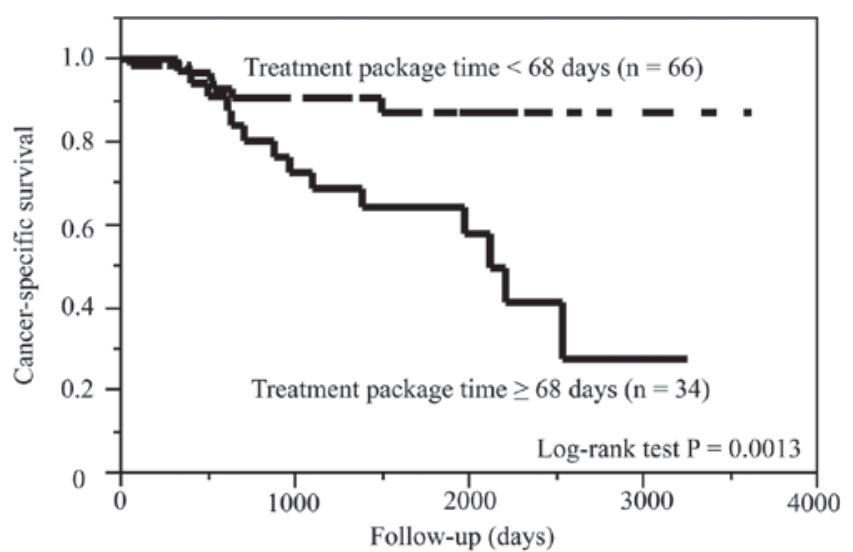

Figure 3. Association between the treatment package time and cancer-specific survival in 100 patients with resectable locally-advanced laryngeal squamous cell carcinoma. Log-rank teat of Kaplan-Meier survival curves shows that the cancer-specific survival was significantly shorter for a treatment package time of $\geq 68$ days than for a treatment package time of $<68$ days.

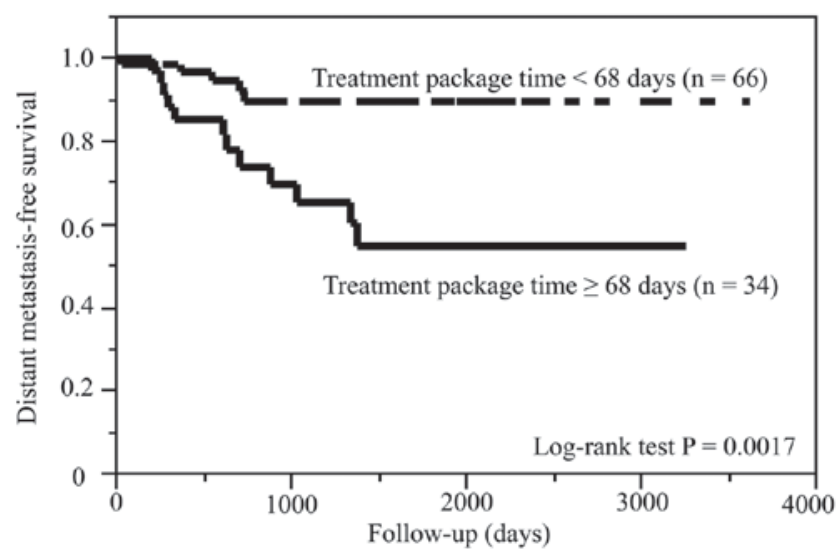

Figure 4. Association between treatment package time and distant metastasis-free survival in 100 patients with resectable locally-advanced laryngeal squamous cell carcinoma. Log-rank test of Kaplan-Meier survival curves shows that distant metastasis-free survival was significantly shorter for a treatment package time of $\geq 68$ days than for a treatment package time of $<68$ days. 
Table II. Association between treatment package time ( $<68$ days $/ \geq 68$ days) and clinical characteristics in laryngeal squamous cell carcinoma.

Treatment package time

\begin{tabular}{|c|c|c|c|c|}
\hline \multirow[b]{2}{*}{ Clinical characteristics } & \multirow[b]{2}{*}{ Total, $\mathrm{n}=100$} & & \multirow[b]{2}{*}{ P-value } \\
\hline & & $<68$ days, $\mathrm{n}=66$ & $\geq 68$ days, $n=34$ & \\
\hline cT, cT3/cT4 & $72 / 28$ & $47 / 19$ & $25 / 9$ & 1.00 \\
\hline $\mathrm{cN}, \mathrm{cN} 0-1 / \mathrm{cN} 2-3$ & $72 / 28$ & $53 / 13$ & $19 / 15$ & 0.02 \\
\hline cStage, cStageIII/cStageIV & $57 / 43$ & $41 / 25$ & $16 / 18$ & 0.20 \\
\hline Subsite, glottis/others & $32 / 68$ & $25 / 41$ & $7 / 27$ & 0.11 \\
\hline Vocal cord fixtation, presence/absence & $44 / 56$ & $30 / 36$ & $14 / 20$ & 0.83 \\
\hline Charlson comorbidity index, $0 / \geq 1$ & $37 / 63$ & $25 / 41$ & $12 / 22$ & 0.83 \\
\hline Gender, male/female & $94 / 6$ & $62 / 4$ & $32 / 2$ & 1.00 \\
\hline Age, $<68 / \geq 68$ & $49 / 51$ & $28 / 38$ & $21 / 13$ & 0.09 \\
\hline Adjuvant treatment, presence/absence & $16 / 84$ & $3 / 63$ & $13 / 21$ & $<0.01^{\mathrm{a}}$ \\
\hline \multicolumn{5}{|l|}{ Treatment group } \\
\hline Total laryngectomy/non-total laryngectomy & $27 / 73$ & $26 / 40$ & $1 / 33$ & $<0.01^{\mathrm{a}}$ \\
\hline Induction therapy/non-induction therapy & $54 / 46$ & $24 / 42$ & $30 / 4$ & $<0.01^{\mathrm{a}}$ \\
\hline
\end{tabular}

${ }^{\mathrm{a}} \mathrm{P}<0.05$.

Table III. Multivariate analysis for CSS and DMFS in laryngeal squamous cell carcinoma.

A, Model-1

\begin{tabular}{|c|c|c|c|c|c|c|}
\hline \multirow[b]{2}{*}{ Clinical characteristics } & \multicolumn{3}{|c|}{ CSS } & \multicolumn{3}{|c|}{ DMFS } \\
\hline & HR & $95 \% \mathrm{CI}$ & P-value & HR & $95 \%$ CI & P-value \\
\hline cT, cT3/cT4 & 0.89 & $0.34-2.47$ & 0.81 & 0.96 & $0.35-2.74$ & 0.93 \\
\hline $\mathrm{cN}, \mathrm{cN} 0-1 / \mathrm{cN} 2-3$ & 0.33 & $0.12-0.86$ & $0.02^{\mathrm{a}}$ & 0.11 & $0.03-0.36$ & $<0.01^{\mathrm{a}}$ \\
\hline Treatment package time, $<68$ days $/ \geq 68$ days & 0.14 & $0.03-0.45$ & $<0.01^{\mathrm{a}}$ & 0.15 & $0.03-0.59$ & $<0.01^{\mathrm{a}}$ \\
\hline Treatment group, TL/non-TL & 5.50 & $1.31-23.0$ & $0.02^{\mathrm{a}}$ & 5.94 & $1.16-32.2$ & $0.03^{\mathrm{a}}$ \\
\hline
\end{tabular}

B, Model-2

\begin{tabular}{|c|c|c|c|c|c|c|}
\hline \multirow[b]{2}{*}{ Clinical characteristics } & \multicolumn{3}{|c|}{ CSS } & \multicolumn{3}{|c|}{ DMFS } \\
\hline & HR & $95 \% \mathrm{CI}$ & P-value & HR & $95 \% \mathrm{CI}$ & P-value \\
\hline cT, cT3/cT4 & 0.64 & $0.23-1.86$ & 0.40 & 0.77 & $0.27-2.28$ & 0.63 \\
\hline $\mathrm{cN}, \mathrm{cN} 0-1 / \mathrm{cN} 2-3$ & 0.30 & $0.11-0.79$ & $0.01^{\mathrm{a}}$ & 0.11 & $0.03-0.36$ & $<0.01^{\mathrm{a}}$ \\
\hline Treatment package time, $<68$ days $/ \geq 68$ days & 0.08 & $0.02-0.28$ & $<0.01^{\mathrm{a}}$ & 0.16 & $0.04-0.56$ & $<0.01^{\mathrm{a}}$ \\
\hline Treatment group, induction/non-induction & 0.09 & $0.02-0.30$ & $<0.01^{\mathrm{a}}$ & 0.19 & $0.05-0.72$ & $0.02^{\mathrm{a}}$ \\
\hline
\end{tabular}

${ }^{\mathrm{a}} \mathrm{P}<0.05$. CSS, cancer-specific survival; DMFS, distant metastasis-free survival; TL, total laryngectomy; HR, hazards ratio; $95 \% \mathrm{CI}$, 95\% confidence interval.

been previously investigated in resectable LALSCC. Thus, we considered that there was a need for such an analysis.

Overall treatment time, which is calculated the same as the TPT, had been shown by several authors to be a significant prognostic factor in various types of cancer $(3,4,7,8,10)$. For example, an overall treatment time of $<80$ days for chemoselection was significantly correlated with longer CSS in patients with squamous cell carcinomas of pharynx and larynx (3). The findings of the present study revealed significant associations between prolonged TPT and shorter CSS and are in good agreement with the results of the previous study (3). 
Although the present study for patients with consecutively various treatments investigated in comparison with previous study for head and neck cancer with adjuvant chemoradiotherapy following surgery, both present and previous studies showed similar findings of the significant association between better survival outcomes and shorter TPT (15).

Soyfer et al (8), reported that the duration of postoperative $\mathrm{RT}$ in days was significantly correlated with distant recurrence in gastric cancer. The findings of the present study revealed significant associations between prolonged TPT and shorter DMFS and are in good agreement with the results of the previous study (8).

Because distant metastasis is directly correlated with CSS in LALSCC (2), we hypothesized that TPT is correlated with DMFS. Indeed, in the present study, we showed that prolonged TPT was significantly associated with shorter DMFS. The findings from the present study suggested that the TPT in LALSCC is a prognostic factor for identifying groups that are at a high-risk of developing distant metastasis. Moreover, we thought that the significant association between a TPT of $\geq 68$ days and a shorter CSS was caused by a shorter rate of DMFS.

In the present study, the TPT $<68$ days with good prognosis shows that definitive treatment with shorter TPT is important. We considered that the cut off at 68 days is an important day, because this contained not only surgery but also surgery and RT or CRT. We considered that TPT $68 \geq$ days results in a shorter prognosis in the present study, because the patients with TPT $68 \geq$ days was significantly associated with more frequent cN2-3 and adjuvant treatment. From the significant association between TPT and survival outcomes in the present study, we suggest that it is essential to perform definitive treatment with shorter TPT as the true meaning in the head and neck treatment. In the present study, the cut-off date (68 days) was experimentally determined by ROC analysis using TPT as continuous variables.

The present study is examined whether the TPT predicts CSS and distant metastasis in laryngeal cancer. A limitation of this study is that the backgrounds of patients in the compared groups are very different. Patients with advanced cancer may have cancer specific-deaths and metastases at a higher rate than those with less advanced cancer. The limitations of this study were the retrospective design and the relatively small number of subjects. A future prospective study on a large cohort in a multi-institutional setting would yield more accurate results. In a future study regarding the effect of TPT, the background factors of patients in the study should be matched.

In conclusion, the present study demonstrated that a prolonged TPT was a prognostic factor of shorter CSS and DMFS in patients with resectable LALSCC who consecutively underwent various treatments modalities, including surgery alone and salvage surgery for residual tumor.

\section{Acknowledgements}

Not applicable.

\section{Funding}

The present study was by the JSPS KAKENHI (grant no. 16K11253).

\section{Availability of data and materials}

The datasets used and/or analyzed during the present study are available on reasonable request from the corresponding author.

\section{Authors' contributions}

HS designed the study, acquired and analyzed the data, drafted the manuscript, and is accountable for all aspects of the study. HTe, NH, DN, YusK, SB, TK, HTac, YutK and HTan acquired the data and critically revised the manuscript. YH designed the study and acquired the data. All authors read and approved the final manuscript.

\section{Ethics approval and consent to participate}

The present study was approved by the review board of Aichi Cancer Center Hospital (Nagoya, Japan), and informed consent for the examinations and treatments was obtained from all of the patients.

\section{Patient consent for publication}

Not applicable.

\section{Competing interests}

The authors declare that they have no competing interests.

\section{References}

1. Sanabria A, Chaves ALF, Kowalski LP, Wolf GT, Saba NF, Forastiere AA, Beitler JJ, Nibu KI, Bradford CR, Suárez C, et al: Organ preservation with chemoradiation in advanced laryngeal cancer: The problem of generalizing results from randomized controlled trials. Auris Nasus Larynx 44: 18-25, 2017.

2. Eskiizmir G, Tanyeri Toker G, Celik O, Gunhan K, Tan A and Ellidoluz H: Predictive and prognostic factors for patients with locoregionally advanced laryngeal carcinoma treated with surgical multimodality protocol. Eur Arch Otorhinolaryngol 274: 1701-1711, 2017.

3. Semrau S, Schmidt D, Lell M, Waldfahrer F, Lettmaier S, Kuwert T, Iro H and Fietkau R: Results of chemoselection with short induction chemotherapy followed by chemoradiation or surgery in the treatment of functionally inoperable carcinomas of the pharynx and larynx. Oral Oncol 49: 454-460, 2013.

4. Sher DJ, Posner MR, Tishler RB, Sarlis NJ, Haddad RI, Holupka EJ and Devlin PM: Relationship between radiation treatment time and overall survival after induction chemotherapy for locally advanced head-and-neck carcinoma: A subset analysis of TAX 324. Int J Radiat Oncol Biol Phys 81: e813-e818, 2011.

5. Budach W, Bölke E, Kammers K, Gerber PA, Orth K, Gripp S and Matuschek C: Induction chemotherapy followed by concurrent radio-chemotherapy versus concurrent radio-chemotherapy alone as treatment of locally advanced squamous cell carcinoma of the head and neck (HNSCC): A meta-analysis of randomized trials. Radiother Oncol 118: 238-243, 2016.

6. Nakata Y, Ijichi K, Hanai N, Nishikawa D, Suzuki H, Hirakawa H, Kodaira T, Fujimoto Y, Fujii T, Miyazaki T, et al: Treatment results of alternating chemoradiotherapy with early assessment for advanced laryngeal cancer: A multi-institutional phase II study. Auris Nasus Larynx 44: 104-110, 2017.

7. Shaikh T, Handorf EA, Murphy CT, Murphy CT, Mehra R, Ridge JA and Galloway TJ: The impact of radiation time on survival in patients with head and neck cancer. Int J Radiat Oncol Biol Phys 96: 967-975, 2016.

8. Soyfer V, Geva R, Michelson M, Inbar M, Shacham-Shmueli E and Corm BW: The impact of overall radiotherapy treatment time and delay in initiation of radiotherapy on local control and distant metastases in gastric cancer. Radiat Oncol 9: 81, 2014. 
9. Peters LJ and Withers HR: Applying radiobiological principles to combined modality treatment of head and neck cancer-the time factor. Int J Radiat Oncol Biol Phys 39: 831-836, 1997.

10. Guttmann DM, Kobie J, Grover S, Lin A, Lukens JN, Mitra N, Rhodes KV, Feng W and Swisher-McClure S: National disparities in treatment package time for resected locally advanced head and neck cancer and impact on overall survival. Head Neck 40: 1147-1155, 2018.

11. Takehana K, Kodaira T, Tachibana H, Kimura K, Shimizu A, Makita C, Tomita N, Nishikawa D, Suzuki H, Hirakawa H, et al: Retrospective analysis of the clinical efficacy of definitive chemoradiotherapy for patients with hypopharyngeal cancer. Jpn J Clin Oncol 46: 344-349, 2016.

12. Suzuki H, Hanai N, Nishikawa D, Fukuda Y and Hasegawa Y: Complication and surgical site infection for salvage surgery in head and neck cancer after chemoradiotherapy and bioradiotherapy. Auris Nasus Larynx 44: 596-601, 2017.
13. Nakata Y, Hanai N, Nishikawa D, Suzuki H, Koide Y, Fukuda Y, Nomura M, Kodaira T, Shimizu T and Hasegawa Y: Comparison between chemoselection and definitive radiotherapy in patients with cervical esophageal squamous cell carcinoma. Int J Clin Oncol 22: 1034-1041, 2017.

14. Polesel J, Furlan C, Birri S, Giacomarra V, Vaccher E, Grando G, Gobitti C, Navarria F, Schioppa O, Minatel E, et al: The impact of time to treatment initiation on survival from head and neck cancer in north-eastern Italy. Oral Oncol 67: 175-182, 2017.

15. Ghanem AI, Mannari A, Schymick MA, Burmeister C, Ghanem T, Chang $\mathrm{S}$ and Siddiqui $\mathrm{F}$ : The effect of treatment package time in head and neck cancer patients treated with adjuvant radiation therapy and concurrent systemic therapy. Int J Radiat Oncol Biol Phys 99: E338, 2017. 